Cuad. Invest. Filol., 43 (2017), 73-92. http://doi.org/10.18172/cif.3006

\title{
EL LÉXICO COLOQUIAL ARGENTINO EN LOS SKETCHES HUMORÍSTICOS
}

\author{
David Giménez Folqués
}

Universitat de València

David.Gimenez-Folques@uv.es

\begin{abstract}
RESUMEN: En la lengua española encontramos una gran riqueza dialectológica y es, precisamente, esa variedad la que explica la existencia de identidades lingüísticas en cada una de las comunidades hispanas. Mediante el léxico coloquial, podemos observar uno de los ámbitos más diferenciales $y$, por lo tanto, identitarios en cada una de esas comunidades; de hecho, para este artículo se propone analizar, concretamente, el léxico coloquial argentino. Siguiendo esta búsqueda lingüística de lo propio, se ha trabajado sobre un contexto donde el registro sea actual, popular y coloquial, como es el caso del ámbito humorístico. De esta manera, nos proponemos en este trabajo encontrar aquellas voces propias del español coloquial argentino en una selección de sketches cómicos actuales.

PALABRAS CLAVE: ámbito cómico, español coloquial, léxico argentino, lexicología, sketch cómico, lenguaje humorístico.
\end{abstract}

\section{ARGENTINE LEXICON IN THE HUMOROUS SPEECH}

ABSTRACT: In the Spanish language there is a great dialectal variety which explains the existence of linguistic identities in each Hispanic community. We can see, through the lexicon, one way to find this linguistic identity. Particulary, we research on the Argentine lexicon, and specifically the case of the Argentine sketches in comic speech. Therefore, the aim of this work will be to find those typical words or expressions of the Argentine language on a selection of comic sketches.

KEYWORDS: Argentine lexicon, colloquial Spanish, comic context, lexicology, sketch, humorous speech.

Recibido: 30/03/2016. Aceptado: 14/07/2016

\section{Introducción}

La riqueza lingüística de la lengua española es un hecho constatable en las diferentes variantes panhispánicas existentes, tanto en España como en América. Desde el origen de estas variedades, cada una de ellas ha estado buscando su 
identidad, es decir, su contexto diferencial con respecto al resto, como señala Aleza (2010). En todos los niveles lingüísticos podemos observar esta diversidad, aunque es en el léxico donde encontramos una mayor diferencia.

Por otro lado, el registro formal suele unificar la lengua hacia una forma estándar. Por el contrario, cuanto más distendido sea el ámbito de uso, más rico será el elemento diferencial. De esta manera, un registro informal y popular como el contexto humorístico puede ser apto para trabajar la variedad dialectal y, por lo tanto, como resultado, la lexicología cómica.

En los últimos tiempos, se ha demostrado que el léxico argentino goza de una llamativa particularidad por su divergencia con el resto de variantes, lo que ha provocado un especial interés entre los investigadores, como indica Blanco (1991). Este interés viene ejemplificado en la cantidad de obras lexicográficas que han ido apareciendo en los últimos años sobre las voces argentinas, como es el caso del Diccionario integral del español de la Argentina de Federico Plager (2010), el Diccionario del habla de los argentinos de la Academia Argentina de Letras (2008) o el Diccionario fraseológico del habla argentina de Pedro Luis Barcia y Gabriela Pauer (2010), entre otros.

Este interés lo recoge Fajardo, destacando la variedad léxica argentina como una de las que más atracción muestran entre los lexicógrafos, lo que demuestra su importancia en el panorama panhispánico:

La peculiar caracterización del léxico diferencial de Argentina es un hecho que se ha venido constatando desde hace tiempo y que se ha corroborado una y otra vez con la publicación de numerosos vocabularios y diccionarios que han hecho de la variedad léxica argentina una de las que cuentan en su haber con una mayor cantidad de obras lexicográficas de todo tipo. Los más recientes de estos trabajos, como el Nuevo Diccionario de Argentinismos de Haensch/Werner (1993), vienen a confirmar que el volumen del léxico diferencial argentino es muy importante cualitativa y cuantitativamente. (1998: 57)

Ante el interés que ha tomado esta particularidad léxica, en este trabajo se va a recoger, clasificar en ámbitos temáticos y analizar las voces argentinas en un contexto oral humorístico como el que representa los sketches cómicos. Se ha elegido el discurso humorístico por la vitalidad y actualidad con la que cuenta en la vigente sociedad. Este ámbito suele ser una buena fuente de uso de voces coloquiales y locuciones fraseológicas en una lengua, por una parte, y de creación neolítica, por otra. Así pues, como señala Ferri y García “el lenguaje cómico es un registro lingüístico próximo a la realidad; por lo que la comedia reproduce el 
habla coloquial, la expresión habitual de una sociedad” (1997: 349). En definitiva, un prometedor campo de estudio para las formas propias y diferenciales de la lengua argentina.

\subsection{El español coloquial como instrumento de estudio}

La variante coloquial, entendida por Briz (1996: 31) como "registro lingüístico usado por los hablantes en situaciones de cotidianidad", resulta una buena fuente de estudio para analizar usos lingüísticos propios en una comunidad específica. Los aspectos de espontaneidad y cotidianidad contribuyen a que los hablantes recurran a formas propias, incluso de nueva creación, como es el caso del léxico propio. Vigara (2005) apoya esta afirmación y apunta, en el caso del español coloquial, que se pueden observar recursos lingüísticos propios según en la sociedad que se empleen, como sería el caso que aquí nos ocupa. De este modo, el registro coloquial resulta adecuado para encontrar elementos divergentes entre las variedades, en este caso panhispánicas, como ya mencionaba Borello para el caso argentino; este autor afirma que los investigadores deberían atreverse a emplear el registro coloquial con el fin de poder mostrar las particularidades de su lengua:

Esperamos que a partir de ahora, nuestros escritores sabrán usar nuestros contados rasgos distintivos sin traumas ni agresividades. Que apelarán al vos y al ché con la misma naturalidad con que emplean todas las palabras de su habla cotidiana, y las integrarán en el complejo totalitario y heterogéneo de la lengua literaria. Varias generaciones dc creadores bastarán para instalar definitivamente entre nosotros esta parcela que nos pertenece y que nos distingue honrosamente de nuestros hermanos de lengua y destino. (1972: 51)

El autor ya indicaba algunos rasgos particulares en el ámbito coloquial argentino, como es el caso del voseo pronominal y el vocativo che ${ }^{1}$. Aunque estos elementos lingüísticos ya están plenamente extendidos en el español argentino, se considerarán coloquiales siempre que se mantengan los parámetros de coloquialidad expresados por Briz (2002), estos son: cotidiano, interactivo, informal y espontáneo.

1. Aun así, hay que indicar que lo propio y lo coloquial no son intercambiables en todos los contextos, aunque en este ámbito, como dice Borello (1972), coincidan. 
Los recursos coloquiales son observables en todos los niveles de la lengua, como apuntaba García (2015). Así, realizando un pequeño recorrido² por algunos de los fenómenos coloquiales más destacables en cada nivel lingüístico de la sociedad argentina, e iniciando por el nivel fonético, Aleza (2010) nos muestra, por ejemplo, algunas variaciones fonológicas que son propias del ámbito informal del contexto rioplatense, como es la pérdida de algunas consonantes en posición implosiva, es decir, en posición final de sílaba ${ }^{3}$.

En el ámbito morfosintáctico, destacan, entre otros, los elementos marcados por Borello (1972) como coloquiales. Podemos resaltar el voseo argentino, que, a su vez, puede cumplir los parámetros de coloquialidad, ya que es el empleo preferido por los hablantes argentinos en el ámbito informal. En Buenos Aires ya estaba extendido durante el siglo XVIII, según Lapesa (1970), y desde entonces se utiliza en los contextos informales de la variante argentina ${ }^{4}$, ya que para el registro formal se utiliza el usted. Este voseo suele ser verbal y pronominal: vos cantás.

Por otro lado, en el nivel pragmático resulta frecuente en contextos informales el empleo del vocativo che. Dotado de una unidad melódica propia, aparece aislado de la oración y su ausencia no altera el contenido semántico del enunciado, aunque sí el pragmático con valor apelativo, como señala Albano (1994).

Entre todos los niveles lingüísticos, en el presente trabajo nos hemos centrado en el léxico-semántico, ya que, como apunta García, representa uno de los ámbitos con mayor cantidad de rasgos de coloquialidad y, por lo tanto, en el que encontraremos mayor cantidad de rasgos distintivos con respecto al resto de variantes del español:

En uno de los ámbitos donde más rasgos de coloquialidad encontramos es en el léxico. La marca argótica o jergal, el uso de proformas, frecuencias léxicas y metáforas cotidianas (como por ejemplo: poner los cuernos en vez de engañar, que se considera más propio de un registro formal) ponen de relieve la especificidad de este nivel en el español coloquial. Además, otros factores como la edad, las características socioculturales, la procedencia geográfica de los hablantes e incluso el propio idiolecto pueden ser determinantes a la hora de analizar el uso de este registro. (2015: 6)

2. Este recorrido simplemente va a destacar algunos ejemplos del español coloquial argentino en cada nivel lingüístico, ya que no es el propósito de este trabajo realizar una descripción exhaustiva de fenómenos que vayan más allá del léxico.

3. Para ampliar información véase el capítulo 2 de Aleza (2010).

4. Excepto en algunas zonas norteñas. Véase Aleza (2010) para ampliar información. 
En concreto, en el léxico argentino resulta imprescindible nombrar la influencia que ha tenido el vocabulario de origen lunfardo. Gobello (1996) afirma que desde su aparición en el siglo XIX esta forma lingüística, formada principalmente por un conjunto de vocablos, tiene una gran repercusión en la sociedad argentina. Así mismo, Fajardo indica que estas nuevas palabras acaban convirtiéndose en vocabulario coloquial de uso general para el resto del país:

\begin{abstract}
Si atendemos al número de palabras que son de uso exclusivo en una zona determinada de Argentina, la región del Río de la Plata muestra una escasa particularidad, lo que no quiere decir que no tenga una personalidad propia, antes bien, al contrario. Se trata de la región que exporta al resto del país una parte muy significativa del léxico allí creado, sobre todo en lo que se refiere al de origen jergal (lunfardo), que llega luego a convertirse en vocabulario coloquial. Buena parte de las palabras marcadas como coloquiales tienen su origen en Buenos Aires y desde allí se extienden por todo el resto del país. (1998: 61)
\end{abstract}

El autor señala la importancia de Buenos Aires, en cuanto a influencia lingüística con el resto del país se refiere. Así, a partir de esta influencia, muchos de estos vocablos consiguen extenderse, además de contar con el apoyo de formas artísticas como la literatura o la música, en especial el tango, como apunta Buesa (1987).

\title{
1.2. El discurso humorístico para el análisis del léxico coloquial
}

Tradicionalmente, se ha afirmado que el aspecto irónico y satírico del discurso humorístico puede ser un buen ámbito para analizar la situación social, política y cultural que vive una determinada comunidad. De hecho, Barros asegura que "las manifestaciones humorísticas de un pueblo son un fiel reflejo de su cultura y de su peculiar modo de pensar y sentir" (1990: 255). Además, el autor indica que el humor no es concebido de igual manera en todas las comunidades, por lo que cada cultura puede reflejar un modo distinto de humor. También Iglesias apoya esta afirmación y define al lenguaje humorístico como un ente que aparece como reflejo social e identitario de una comunidad, cuando señala:

Pero el humor también es una especie de espejo -a menudo distorsionador de imágenes que refleja la sociedad de cada época y de cada zona. En el mensaje humorístico, los personajes se consideran a menudo representantes de un grupo, un pueblo, una clase social y sirven para poner de manifiesto el carácter, las preocupaciones o la visión de mundo de ese grupo. (2000: 441) 
Aunque el discurso humorístico tiene muchas facetas, este aspecto propio y diferencial favorece el análisis identitario de una comunidad lingüística determinada. Así mismo, los contextos informales y cotidianos recurrentes en el lenguaje humorístico dan la posibilidad de encontrar un mayor número de voces y expresiones coloquiales, que es el objetivo que aquí nos ocupa. De este modo, Ferri y García (1997) apuntan al ámbito humorístico como una buena fuente de reproducción del habla coloquial.

Por otro lado, el lenguaje cómico tiene unas características propias de creación que hay que tener en cuenta cuando abordemos nuestro objeto de estudio. Como asegura Ferri y García, según sus estudios, hay unas pautas comunes en los diferentes niveles lingüísticos, como serían:

Aspectos fonológicos:

Características propias del dialecto utilizado, como, por ejemplo, “las síncopas, las hablas regionales y la pronunciación descuidada” [...].

Aspectos morfológicos:

El caso del diminutivo, la lexicalización de algunos imperativos, el voseo hispanoamericano, la manera de trocear los lexemas en los nombres propios, el orden de los pronombres, algunos sufijos especiales, etc. [...].

Aspectos léxico-semánticos:

Las expresiones acuñadas por el uso, la ironía, los juegos de palabras y las dilogías... En la adquisición de léxico merecen especial atención los extranjerismos, vulgarismos y expresiones malsonantes. Los vulgarismos y los «tacos» no se pueden marginar en este elenco léxico. (1997: 350-352)

De entre todos estos niveles del lenguaje humorístico, los autores señalan al nivel léxico como el más prolífico en cuanto a creación de elementos, ya que atesora un rico caudal lingüístico; lo que supone, además, un síntoma del dinamismo y viveza en este tipo de discursos.

En este caudal léxico, Alonso destaca la abundancia de palabrotas que podemos encontrar en el lenguaje cómico, y pone como ejemplo los programas cómicos televisivos como origen de muchas de estas voces:

Merece la pena detenerse en un aspecto del español coloquial: el léxico llamado vulgar o «malsonante». Si pasáramos revista al humor televiso de los últimos años en España se podría constatar que gran parte de él utiliza como recurso de comicidad expresiones vulgares, y que eso, además de ser un reflejo de la vida cotidiana, no es sinónimo necesariamente de falta de ingenio o de pobreza lingüística. (2005: 128)

Como observaremos en el trabajo, este tipo de voces resulta un fenómeno recurrente por parte de los humoristas argentinos que las utilizan; aunque no es 
el único fenómeno que vamos a encontrar. Barros (1990: 260) indica otros elementos léxicos que suelen aparecer en este nivel:

Las sufijaciones deformadoras [...]. Las combinaciones inesperadas y sorprendentes de vocablos, la explotación oportunista del doble sentido de las palabras, el juego de la ambigüedad y de la polisemia, el aprovechamiento de los valores figurados ocasionales, apoyados tanto en el contexto situacional y cultural como en el verbal, son una fuente constante de creaciones humorísticas.

Los fenómenos de formación de palabras, derivación, composición y locución sintáctica, tendrán también un calado importante en nuestros resultados. Estas formas buscan aumentar la expresividad y el ingenio en el discurso. Muchas veces recurren a elementos ya existentes, sin embargo, en otras ocasiones lo que se produce son resultados neológicos.

Estos procesos de formación aparecerán en los programas que hemos seleccionado según las características del léxico argentino, que podemos observar en Fajardo (1998). El autor, en primer lugar, apunta que los procesos de derivación y composición son mecanismos generales en la variante argentina. Destaca, por un lado, el uso de los sufijos - $a d a$, -udo- $a$, ero- $a$, iento- $a$; y, por el otro, la recurrencia en el uso de la composición, que tiene como fin la búsqueda de expresividad. Finalmente, menciona los casos de truncamiento e inversión silábica, mecanismos que acompañan a los anteriores en la creación de nuevas palabras.

Otra de las tendencias que encontraremos en este nivel léxico es el empleo de lunfardismos, ya introducido anteriormente como marca de argentinidad. El hecho de que este conjunto de vocablos esté presente en la actualidad, también en los medios de comunicación, representa otro ejemplo de la escalada que han experimentado estas voces desde su origen. Una parte de estos lunfardismos lo conforman préstamos, especialmente procedentes de la lengua italiana. De hecho, como Fajardo afirma, en el ámbito cómico argentino se suele recurrir al préstamo en modo irónico: "Muchas veces se emplean coloquialmente y con un cierto sentido humorístico: ¡andiamo! ‘ivamos!', jatenti! ‘¡ojo!’, falluteli ‘persona informal’, gamba 'pierna’, locatelli ‘loco’, baratieri ‘barato’, etc.” (1998: 58-59).

\section{Objetivos y metodología}

Como hemos señalado, nos proponemos analizar las particularidades del uso del léxico argentino en un ámbito humorístico audiovisual, en concreto hemos 
seleccionado una serie de sketches cómicos a partir de realizaciones populares y actuales, en concreto: Peter Capusotto y Sus Videos (sketches de 2015), Cualca (sketches de 2014-2015), y Peligro sin codificar (sketches de 2015). Además del contexto popular y actual que nos brindaban estas series, también han sido elegidas por la cantidad de palabras y expresiones propias a las que recurren en cada capítulo; así mismo incluyen, en muchas ocasiones, situaciones informales y cotidianas.

Entre las tres realizaciones se ha analizado un total de 48 capítulos, de los que se han obtenido 214 voces de uso diferencial en el español de Argentina, divididos en lunfardismos; léxico propio no lunfardo y frases hechas; y anglicismos, dado que la cantidad de voces permitía la formación de cada uno de estos tres apartados.

Una vez recogidas las voces había que constatar hasta qué punto eran propias de Argentina o, por el contrario, eran voces que se encontraban, además, en otras zonas hispanohablantes. De este modo, el presente corpus ha pasado el filtro de diccionarios, por un lado, específicos sobre el español de Argentina: el Diccionario del habla de los argentinos (2008) ${ }^{5}$, el Diccionario fraseológico del habla argentina (2010) ${ }^{6}$ y el Gran diccionario de los argentinos (2011) ${ }^{7}$; y, por el otro, generales: el Diccionario de americanismos (2010) ${ }^{8}$ y el Diccionario de la Real Academia (2014) 9 .

En segundo lugar, resultaba interesante conocer el ámbito temático de estas voces, es decir, cuál es la temática predominante en el ámbito del lenguaje humorístico argentino. Los resultados fueron aproximadamente los esperados en un contexto informal de estas características, ya que las temáticas predominantes fueron las del sexo, droga, insultos y dinero. Estos ámbitos, además, suelen ser prolíficos en el lunfardo argentino, dado que esta jerga se originó entre los estratos sociales bajos.

Para llevar a cabo todos estos parámetros se analizaron las voces resultantes mediante fichas lexicográficas. En estas fichas se tuvieron en cuenta todos los objetivos que se querían alcanzar como, por ejemplo, tipo de fenómeno lingüístico, voz general o específica y ámbito temático. Por consiguiente, desarrollamos los siguientes apartados:

\footnotetext{
5. En las fichas (DHA).

6. En las fichas (DFHA)

7. En las fichas (GDA).

8. En las fichas (DA).

9. En las fichas (DRAE).
} 
voz o expresión;

fuente;

contexto;

campo temático;

equivalente peninsular;

GDA, DHA, DFHA;

$D A$;

DRAE;

observaciones $^{10}$.

Tabla 1. Ejemplo de ficha lexicográfica

\begin{tabular}{|l|l|}
\hline voz o expresión & laburo \\
\hline fuente & Peligro Sin Codificar: “Los pilotos del escándalo buscan laburo” (julio 2015) \\
\hline contexto & Los pilotos del escándalo buscan laburo. \\
\hline campo temático & trabajo \\
\hline equivalente peninsular & Curro, trabajo \\
\hline$G D A, D H A, D F H A$ & $\begin{array}{l}\text { m. coloq. Trabajo: Ahora estoy sin laburo./ Tengo un montón de laburo } \\
\text { atrasado. / Quisiera conseguirme un laburito. / Es el último día de } \\
\text { laburo, mañana salgo de vacaciones (GDA). } \\
\text { m. coloq. Trabajo: Mirá, ando buscando otro laburo y pensé que en su } \\
\text { taller... (DHA). }\end{array}$ \\
\hline$D A$ & 1. m. Ec., Bo., Ch., Py., Ar., Ur. Trabajo, empleo. pop. \\
\hline$D R A E$ & 1. m. coloq. Arg. y Ur. trabajo (\| ocupación retribuida). \\
\hline observ & \\
\hline
\end{tabular}

En definitiva, mediante la recogida de este corpus y su análisis a partir de fichas lexicográficas, tratamos de vislumbrar la cantidad y el tipo de léxico argentino que existe en la actualidad en el lenguaje humorístico.

10. En las observaciones se han consultado otras obras como la Ortografía de la lengua española (2010a) o la Nueva gramática de la lengua española (2010b). 


\title{
3. Tipo lingüístico de voces argentinas en el léxico humorístico
}

\subsection{Lunfardismos}

El lunfardo responde a aquella jerga que se crea a finales de siglo XIX en la ciudad de Buenos Aires, entre los estratos bajos de la sociedad. En principio estaba formado por una serie de voces que pertenecían a un campo reducido, como era el de la delincuencia, la prostitución, la droga, la comida, el dinero, el sexo...; pero este caudal léxico fue aumentando ante el interés del contexto cultural argentino, por representar el habla de esos estratos sociales bajos de la sociedad de su tiempo. Como indica Buesa (1987), mediante la literatura, el teatro y la música, donde juega un papel destacado el tango, este caudal léxico cobra mayor interés. De este modo fue escalando hasta las capas superiores de la sociedad para llegar al vocabulario general no solo de Argentina, sino también del vocabulario español panhispánico ${ }^{11}$ :

\begin{abstract}
Al ser solamente un vocabulario, un conjunto de palabras (5000, quizá), es imposible hablar en lunfardo; sí es posible, en cambio, hablar con lunfardo. Esos miles de palabras son insuficientes para expresar la cantidad de ideas que, por pocas que sean, tiene una persona. Además, no sólo las palabras lunfardas son sinónimas de las castellanas, sino que son sinónimas entre sí: del total de palabras, una gran cantidad -una proporción mucho mayor que la del castellano- está referida al sexo, a las distintas partes del cuerpo, la comida, la bebida, el dinero, la ropa, el delito. De hecho, la imposibilidad de hablar en lunfardo es tan evidente que quienes usamos sus palabras, todos los porteños, en mayor o menor medida, usamos un porcentaje más o menos bajo de los términos lunfardos que conocemos (dependerá del contexto, del interlocutor, etc.). (Gobello, 1996: 2)
\end{abstract}

Así mismo, hoy en día encontramos voces del lunfardo en situaciones cotidianas del español de Argentina y, debido a la temática en la que suelen aparecer, también en el lenguaje humorístico de las series de televisión. Por otro lado, los italianismos tienen un gran peso en el conjunto léxico del lunfardo, ya que en el origen de esta variante jergal los inmigrantes italianos tuvieron un papel decisivo, como afirma Fajardo:

11. Por otro lado, López (2000) reivindica el papel del lunfardismo en la sociedad, citando a Gobello (1996). 
La contribución italiana se ha dado en todos los niveles, pero en la lengua popular y en la jerga la influencia ha sido más intensa y ha resultado muy importante en la formación del llamado lunfardo: de las 560 palabras lunfardas contenidas en el Lunfa básico de Tino Rodríguez (1981) unas 80 proceden del italiano. (1998: 58)

Para detectar el verdadero origen lunfardo de estas voces acudimos a diccionarios especializados de lunfardo como el de Gobello (1999). A continuación incluimos los lunfardismos analizados:

1) bife, cachucha, chabón/a, chanchada, chancho, chimento, chucho, cimarrón, coso, deschavarse, encarajinarse, espamentoso/a, forro, gambeta, garrón, gil, guacho/a, guarango/a, laburo, mango, mina, orto, piantarse, pibe, piola, rajar, reventado/a, tomársela, turro/a.

Del anterior listado podemos observar, efectivamente, que el léxico lunfardo habla de la temática del dinero y trabajo: laburo (trabajo), mango (dinero); sexo: cachucha (vagina), forro (preservativo), orto (culo); drogadicción: reventado/a (deterioración producida por las adicciones); insultos: gil (tonto), turro/a (tonto) y violencia: bife (guantazo), rajar (agresión física, normalmente mediante un arma blanca); usados en el contexto cómico como representación de situaciones donde encontramos hablantes en un registro informal.

También podemos constatar la presencia de italianismos que, como ya hemos comentado, responde a la llegada de esta inmigración europea a finales del siglo XIX y su consiguiente influencia lingüística, en este caso léxica. Encontramos voces como laburo (del italiano lavoro) y yirar (del italiano girare). Resulta lógica, además, su aparición, ya que autores como Fajardo (1998) señalan que estas voces ocupan un $32 \%$ del total de extranjerismos en el español de Argentina.

\subsection{Léxico propio no lunfardo y frases hechas}

En segundo lugar, nos encontramos con un conjunto de voces que no proceden del lunfardo (aunque algunas sí pueden llegar a ser derivaciones de la jerga). Este grupo de voces y frases hechas está compuesto por coloquialismos propios del español de Argentina, arcaísmos, derivaciones, composiciones y frases hechas. La mayoría son de uso común en un registro informal y algunas otras representan recursos o neologismos propios de este lenguaje humorístico, por lo que algunos de ellos no son recogidos por los diccionarios que hemos propuesto en la metodología. 
Tienen un papel destacado las denominadas malas palabras. Para disminuir el impacto de estas voces, es frecuente el recurso del eufemismo:

En cuanto al léxico considerado vulgar e incluso el que tiene un uso tabuizado está muy presente en el habla coloquial argentina y como contrapunto, el recurso al eufemismo es constante. Las llamadas puteadas, las malas palabras, que van desde insultos como el conocido boludo hasta un variadísimo repertorio de designaciones y calificaciones con referencias sexuales: poronga 'órgano sexual masculino', concha ‘órgano sexual femenino', mineta ‘tipo de sexo oral’ y que darían material abundante para extensas monografías sobre la creación y motivación léxica (Fajardo, 1998: 66).

Por lo tanto, vamos a observar las voces que pertenecen a este segundo grupo donde resaltan, entre ellas, las llamadas puteadas:

2) a la gilada ni cabida, al pedo, al toque, atajar un penal, bancarse, bardear, bebo/a, boludez, boludo/a, bombacha, botinera, buraco, burro de arranque, cagar a piñas, cagarse de risa, cebar, che, cheto/a, chimichurri, choripán, chupapija, coger, comeviejas, conchudo/a, copado/a, cuadra, cueva, dale, endrogarse, estar duro/a, flaco/a, groso/a, hacer pelota, gamba, la cola pide, la concha de la Lora, la concha de tu madre, loco/a, la puta que te parió, lechuga, lola, llamado, medias, medibacha, micro, morocho/a, morochongo/a, negro/a, onda, paco, palomita, pancho, papu, pelotudez, pepa, pete, pilotear, puto, recibirse, remís, revolver el estofado, seca, ser un/a calienta pava, ser un/a capo, ser un/a pajarón/a, ser un/a ratón/a, ser un/a sorete, sin remate, renguera, subte, tatú carreta, te debo una de vuelta, tuquera, yerba, zarpado/a.

Destaca en este grupo la presencia de derivados que pueden llegar a formar nuevas palabras, quizás con una nueva connotación e incluso un nuevo significado, como, por ejemplo: endrogarse (de drogarse); boludez (de la forma boludo/a, con el significado de 'tontería'), pelotudez (de pelotudo, con el significado de 'tontería'), conchudo/a (de concha, con el significado de 'cabrón/a’).

También encontramos la aportación de neologismos mediante las palabras compuestas. Tenemos los siguientes ejemplos: burro de arranque (motor del coche), comeviejas (persona a la que le gusta tener relaciones con personas de mayor edad), tatu carreta (tipo de armadillo), choripán (sándwich de chorizo y pan), chupapija (el equivalente peninsular sería chupapollas).

Por otro lado, el grupo de expresiones ocupa un lugar notable en este apartado, la mayoría hacen referencia a insultos o malas palabras y algunas otras tienen que ver con el contexto cultural e histórico argentino: a la gilada ni cabida 
(tonterías las justas), atajar un penal (prepararse para una situación complicada), cagar a piñas (golpear continuadamente a alguien), cagarse de risa (morirse de risa), estar duro/a (persona drogada, a veces puede hacer referencia a la muerte causada por estas sustancias), hacer pelota (destrozar, arruinar), la cola pide (persona predispuesta a tener sexo), la concha de la Lora (expresión recurrente para faltar al respeto a alguien. También para mostrar desacuerdo o sorpresa), la concha de tu madre (expresión recurrente para faltar al respeto a alguien. También para mostrar desacuerdo o sorpresa), la puta que te parió (expresión recurrente para faltar al respeto a alguien. También para mostrar desacuerdo o enojo), revolver el estofado (tener relaciones sexuales), te debo uno de vuelta (deber algo a alguien).

Mención aparte, por su importancia, merecen las designaciones despectivas. De entre ellas destacan ser un/a calienta pava (en un contexto peninsular calienta braguetas, es decir, 'persona que provoca sexualmente'), ser un/a pajarón/a (persona tonta o ingenua), ser un/a ratón/a (persona tacaña), ser un/a sorete (en un contexto peninsular ser un/a mierda).

En menor medida, podemos encontrar locuciones preposicionales, principalmente introducidas por la preposición $a+$ artículo + sustantivo, como en al pedo (hacer algo tontamente), o al toque (realizar una acción instantáneamente).

Como hemos podido comprobar, la temática predominante es la de insultos o puteadas. Voces y expresiones ya comentadas como la concha de la Lora, la concha de tu madre, la puta que te parió, boludo/a, conchudo/a, puto, etc., resultan útiles para el discurso cómico de estos sketches donde se muestra enojo o sorpresa, desaprobación o falta de respeto. En segundo lugar, la temática del sexo también cuenta con un buen número de voces: coger (realizar el acto sexual), revolver el estofado (realizar el acto sexual), pete (felación), comeviejas (persona a la que le gusta mantener relaciones con personas mayores), cueva (vagina). Finalmente, el tema de la drogadicción tiene, de nuevo, protagonismo: endrogarse (drogarse), estar duro/a (persona drogada, a veces puede hacer referencia a la muerte causada por estas sustancias), tuquera (boquilla para fumar marihuana), paco (deshecho de la cocaína).

\subsection{Anglicismos}

En el español argentino podemos encontrar diferentes contactos lingüísticos con otras lenguas. Por un lado, contacto con lenguas indígenas en el noreste en contacto con Paraguay, en el noroeste en contacto con Bolivia y en el sur en 
contacto con Chile, entre otros. Por otro lado, contacto con lenguas modernas como el italiano ${ }^{12}$, principalmente a través de lunfardismos, el francés, el alemán o el inglés. Como sucede de manera general, los anglicismos tienen mucho peso en el ámbito panhispánico ${ }^{13}$, principalmente en América. Esto sucede por la fuerte influencia de Estados Unidos, también en el ámbito lingüístico, como afirma Aleza (2010). Las principales temáticas donde encontramos estas voces son en la gastronomía, el deporte y la informática, además de en otros lenguajes de especialidad como el turismo, la medicina, etc.

Torres Torres (2010) observa cómo en el ámbito americano, y así sucede, también, en Argentina, tanto la grafía como la pronunciación del anglicismo se acerca mucho más al original que en un contexto peninsular. Este hecho está motivado por la mayor presencia de Estados Unidos en todo el continente americano con respecto al ámbito peninsular, aunque encontremos ejemplos de adaptación por la extensión en su uso.

A partir del análisis de los sketches cómicos analizados estos son los anglicismos que hemos encontrado:

3) barbecue, bartender business, cash, cross-fit, estar a ful, fat, free-shop, gym, hot, light, man, mod-town, restauran, party, pop-dancing, pool, room, sandwich, shopper, shopping, show, showman, spot, traffic, whatever.

En primer lugar, aparecen expresiones de uso habitual que proceden del inglés o que contienen, al menos, una palabra en inglés. Como apunta Torres Torres (2010) no se puede hablar de spanglish, como sí sucede en otros países como Puerto Rico o Estados Unidos donde el contacto entre el español y el inglés es mayor, pero, ocasionalmente, encontramos expresiones donde es evidente el contacto entre las dos lenguas como estoy a ful (estar muy ocupado/a o lleno/a de actividad) o no tengo cash (no disponer de dinero en efectivo).

Los campos predominantes son los esperados: el deporte (cross-fit, gym, pool), la gastronomía (barbecue, bar-tender, light, restauran, sandwich), el dinero (business, cash), el ámbito festivo (party, pop-dancing) y el ámbito de las compras (shopping, free shop, shopper).

12. Vistos en el apartado de lunfardismos.

13. Este hecho lo podemos observar en la cantidad de anglicismos que se recoge en Real Academia Española (2005). 
Llama la atención, con respecto a un ámbito peninsular, que algunos de estos préstamos se usen, ya que existen equivalentes en la lengua española con vitalidad en su empleo. Sería el caso de room (en lugar de pieza o habitación), barbecue (en lugar de parrilla o barbacoa), business (en lugar de negocio), fat (en lugar de gordo/a), gym (en lugar de gimnasio), hot (en lugar de caliente), party (en lugar de fiesta), pool (en lugar de billar), show (en lugar de espectáculo), o traffic (en lugar de tráfico). En todas estas voces, en un contexto peninsular se usaría el equivalente en lengua española, salvo en alguna excepción donde también se usa el préstamo original, sería el caso de shopping, sandwich o show. Aunque encontramos aquí otra evidencia del mayor contacto de la lengua inglesa en zonas americanas con respecto a la zona peninsular, hay que tener en cuenta que el uso de estos anglicismos puede ser intencionado por parte del discurso humorístico, con el fin de aumentar la expresividad o el tono jocoso de la voz o expresión.

\section{Diccionario general / específico}

Uno de los aspectos más interesantes en este estudio era saber si el discurso cómico argentino usaba términos extendidos en cuanto a uso y, por lo tanto, recogidos por los diccionarios académicos más reconocidos, sobre todo en el Diccionario de americanismos (2010), o si por el contrario usaban voces localistas que solamente encontraríamos en diccionarios específicos como el Gran diccionario de los argentinos (2011) o el Diccionario fraseológico del habla argentina (2010). Podríamos considerar, por otro lado, que la voz representaría un neologismo propio de este género si no apareciese en ningún diccionario, ni siquiera en uno específico.

\subsection{Argentinismos en el Diccionario de americanismos}

El Diccionario de americanismos representa la mayor obra en cuanto a recogida de voces procedentes del español de América ${ }^{14}$. Responde a un trabajo exhaustivo de colaboración entre las academias del mundo hispánico: Asociación de Academias de la Lengua Española (ASALE). En este Diccionario podemos encontrar no solo las voces propias del español de América, sino también las acepciones que esa misma voz tiene en las diferentes zonas panhispánicas, incluida España.

14. En Aleza (2010) y Andión Herrero (2004) encontramos la justificación a por qué es importante disponer de un diccionario de estas características. 
Así pues, esta obra va a recoger los argentinismos de uso común con la marca $A r$. De este modo, sabremos que nos encontramos ante voces, aunque propias de Argentina, compartidas con otras zonas hispanohablantes o, por otro lado, locales pero con una extensión de uso reconocida. En nuestro corpus aparecen recogidas por el Diccionario las siguientes voces:

4) al pedo, al toque, bancarse, barbecue, bardear, bartender, bife, boludez, boludo/a, bombacha, burro de arranque, cachucha, cagarse de risa, cash, cebar, che, chabón, chancho, chanchada, cheto/a, chimento, chimichurri, choripán, chucho, chupapija, cimarrón, coger, conchudo/a, copado/a, coso, cuadra, cueva, deschavarse, encarajinarse, endrogarse, espamentoso/a, estar a ful, estar duro/a, fat, flaco/a, forro, gambeta, garrón, groso/a, guacho, guarnago/a, hacer pelota, hot, gamba, laburo, la concha de la Lora, la concha de tu madre, loco/a, lechuga, llamado, man, mango, medias, medibacha, micro, mina, morocho/a, negro/a, onda, orto, paco, pancho, party, pelotudez, pepa, pete, piantarse, pibe, pilotear, piola, pool, rajar, recibirse, remís, reventado, sandwich, seca, ser un/a capo, ser un/a pajarón/a, ser un/a ratón/a, ser un/a shopping, show, sorete, renguera, subte, tatú carreta, tomársela, turro, whatever, yerba.

En la anterior lista podemos observar el gran trabajo de recogida de americanismos que ha realizado el Diccionario de americanismos, ya que la mayoría de argentinismos en el discurso humorístico que hemos encontrado aparecen registrados en esta obra; algunos de ellos solamente se dan en Argentina, lo que significa que el alcance del Diccionario es bastante significativo.

\subsection{Argentinismos fuera del Diccionario de americanismos}

En segundo lugar, nos encontramos con aquellas voces que no aparecen recogidas por el Diccionario, pese a que esta obra incluye también localismos. Esto quiere decir que, probablemente, algunas de estas palabras sean neologismos propios del discurso cómico, es decir, no tienen una extensión de uso suficiente, o simplemente no han sido consideradas por la obra. De entre ellas encontramos:

5) a la gilada ni cabida, atajar un penal, bebo/a, botinera, buraco, business, cagar a piñas, chupapija, comeviejas, cross-fit, dale, free-shop, gil/a, gym, la cola pide, la puta que te parió, lechuga, light, lola, mod-town, morochongo/a, palomita, papu, pop-dancing, puto, restauran, revolver el estofado, room, ser un/a calienta pava, shopper, showman, sin remate, spot, te debo una de vuelta, traffic, tuquera, zarpado/a. 
Por un lado, parece lógico que anglicismos de uso particular como cross-fit, free-shop o pop-dancing no aparezcan. Sin embargo, no resulta tan evidente que otros más extendidos en América como gym, business o showman no aparezcan, ya que sí lo hacen, como hemos visto en el listado anterior, hot, party y show. Por otro lado, showman sí aparece en el Gran diccionario de los argentinos, lo que demuestra, como acabamos de afirmar, su extensión de uso, al menos en Argentina.

Así mismo, también de manera lógica encontramos que algunas expresiones no aparecen tampoco en el Diccionario. Es el caso de a la gilada ni cabida, atajar un penal, la cola pide, o sin remate, expresiones propias del español argentino y que tienen poca o ninguna extensión de uso en el resto de países.

Podríamos hablar de otro grupo de voces de nueva creación, dado que no aparecen ni en diccionarios generales ni en diccionario específicos. Sería el caso de morochongo (hombre moreno y atractivo), comeviejas (persona que mantiene o quiere mantener relaciones con personas más mayores), lechuga (dinero), o papu (expresión cariñosa hacia la pareja masculina). Estas voces de nueva creación pueden ser propias del discurso humorístico o, por otro lado, palabras con un uso reciente en el español de Argentina que todavía no han sido recogidas por los diccionarios académicos.

\section{Conclusiones}

Después de haber observado y analizado el léxico propio del español de Argentina en el discurso humorístico, podemos indicar que goza de una gran vitalidad y personalidad para diferenciarse no solo del español peninsular, sino también del resto de variantes del mundo hispánico. Encontramos muchas voces y expresiones propias del español de Argentina divididas en tres grandes grupos. En primer lugar, lunfardismos como gil (tonto), turro/a (tonto) y bife (guantazo), fenómeno que representa uno de los contextos más representativos en lo propio argentino que se conoce, ya que el lunfardo es un forma lingüística nacida en lo más profundo de Argentina, los bajos fondos de Buenos Aires, y extendida y reconocida por todo el país. Por otro lado, el léxico propio no lunfardo y frases hechas, ámbito más allá de los lunfardismos con derivaciones como boludez (de la forma boludo/a, con el significado de tontería), pelotudez (de pelotudo, con el significado de tontería); compuestos como comeviejas (persona a la que le gusta tener relaciones con personas mayores), tatu carreta (tipo de armadillo), choripán (sándwich de chorizo y pan); y frases hechas del tipo a la gilada ni cabida 
(tonterías las justas), atajar un penal (prepararse para una situación complicada), cagar a piñas (golpear continuadamente a alguien). Y en tercer lugar, un gran uso de anglicismos, comunes y propios en el continente hispanoamericano, con ejemplos como business, cash, cross-fit, o estar a ful. Todos estos fenómenos vienen reforzados por el ámbito cómico que hemos escogido, ya que estas formas de composición, derivación y neología son frecuentes en este tipo de discursos que buscan la innovación, la expresividad y el ingenio.

Al haber elegido el discurso humorístico como modo de transmisión léxica y, en concreto, los sketches cómicos, uno de los ámbitos que más proliferan es el de las palabrotas, malas palabras o puteadas como se suele decir en el español argentino (boludo, la concha de tu madre, la puta que te parió). Es lógico que aparezcan por ser este un discurso con contexto predominantemente informal, que, además, por distendido y cotidiano aumenta las posibilidades de extraer las particularidades léxicas de un idioma, en este caso del español argentino.

Muchas de estas voces están establecidas en el vocabulario común, como es el caso de chimichurri, choripán, laburo; sin embargo, otras resultan genuinas, como morochongo, comeviejas o lechuga (en el sentido monetario), lo que las enmarca en el ámbito de los neologismos, ya sean exclusivas de este discurso, por necesidades del autor o improvisación, o por derivación de términos sí establecidos.

Se ha observado si estas palabras aparecían en diccionarios generales como el Diccionario de americanismos o si, por el contrario, teníamos que recurrir a diccionarios específicos de Argentina, mostrando así el carácter localista o neológico del término. Los resultados han demostrado la gran labor del Diccionario de americanismos, dado que la mayoría de argentinismos ${ }^{15}$ son recogidos por esta obra, demostrando así el exhaustivo trabajo que han realizado. Podemos exceptuar algunos casos en frases hechas como a la gilada ni cabida, atajar un penal, te debo uno de vuelta; algunos anglicismos como cross-fit, free-shop o pop-dancing; o neologismos como los que acabamos de mencionar.

En definitiva, con este trabajo hemos acercado a la comunidad investigadora la actualidad de las voces propias de Argentina, concretamente en el discurso humorístico, ya que este representa un ámbito, además de rico en voces propias, popular y actual. El objetivo es continuar con este trabajo en un futuro y comparar estas voces con otros discursos que también resulten significativos a la hora de encontrar voces propias de la variante argentina.

15. Con la etiqueta $A r$. 


\section{Bibliografía}

ACADEMIA ARGENTINA DE LETRAS (2008). Diccionario del habla de los argentinos, Argentina: Editorial La Nación.

ALBANO DE VÁZQUEZ, H. (1994). “Algunas observaciones acerca del uso del vocativo en el habla infantil rioplatense”. REALE. Revista de estudios de adquisición de la lengua española 2: 9-22.

ALEZA, M. y ENGUITA UTRILLA, J.P. (Coords.) (2010). La lengua española en América: normas y usos actuales. Valencia: Universitat de València.

ALONSO GARCÍA, J. P. (2005). "Riendo se entiende la gente: el humor en la clase de ELE”. Ponencia en Actas XVI Congreso de ASELE, Oviedo.

ANDIÓN HERRERO, M. A. (2004). Variedades del español de América: una lengua y diecinueve países. Brasilia, Consejería de educación en Brasil: Ministerio de Educación y Ciencia de España.

ASOCIACIÓN DE ACADEMIAS DE LA LENGUA ESPAÑOLA (2010). Diccionario de americanismos. Madrid: Santillana.

BARCIA, L. y PAUER G. (2010). Diccionario fraseológico del habla argentina. Argentina: Editorial Emecé.

BARROS GARCÍA, P. (1990). "La connotación contextual en el lenguaje humorístico” en II Congreso nacional de ASELE. Málaga: 255-265.

BLANCO MERCEDES, I. (1991). Lenguaje e identidad. Actitudes lingüísticas en la Argentina 1800-1960. Bahía Blanca: Universidad Nacional del Sur.

BORELLO, R. (1972). "Habla coloquial y lengua literaria en las letras argentinas”. Anales de Literatura Hispanoamericana 1: 5-51.

BRIZ, A. (1996). El español coloquial: situación y uso. Madrid: Arco Libros.

BRIZ, A. (2002). “El léxico coloquial en la conversación”. Textos de didáctica de la lengua y la literatura 31: 10-21.

BUESA, T. (1987). “Lunfardo, jerga del bajo fondo bonaerense”. Español actual: Revista de español vivo 48: 43-58.

FAJARDO, A. (1998). “Aproximación al léxico argentino actual”. Revista de Filología de la Universidad de La Laguna 16: 57-71.

FERRI COLL, J. M. y GARCÍA FERRÓN, E. (1997). "Principios didácticos del lenguaje cómico” en El español como lengua extranjera: del pasado al futuro. Alcalá de Henares: Servicio de Publicaciones Alcalá de Henares: 349-356.

GARCÍA, J. (2015). “Teoría y práctica del español coloquial en el aula de ELE”. RedELE 27: 2-27.

GOBELlO, J. (1996). Aproximación al lunfardo. Argentina: Ediciones de la Universidad Católica Argentina. 
GOBELLO, J. (1999). Nuevo diccionario lunfardo. Argentina: Ediciones Corregidor.

GRUPO CLARÍN (2011). El gran diccionario de los argentinos. Argentina: Editorial Tinta Fresca.

IGLESIAS CASAL, I. (2000). "Sobre la anatomía de lo cómico: recursos lingüísticos y extralingüísticos del humor verbal” en XI Congreso Internacional ASELE. Zaragoza: 439-450.

LAPESA, R. (1970). "Las formas verbales de segunda persona y los orígenes del voseo" en Actas del Tercer Congreso Internacional de Hispanistas. México: 519-533.

LÓPEZ N. (2000). “Qué es el lunfardo” en Academia Porteña del lunfardo. Argentina, <http://geocities.ws/lunfa2000/queesellunfardo.htm>. (Acceso 15 Octubre 2016)

PLAGER, F. (2010). Diccionario integral del español de la Argentina. Madrid: Voz Activa.

REAL ACADEMIA ESPAÑOLA Y ASOCIACIÓN DE ACADEMIAS DE LA LENGUA ESPAÑOLA (2005). Diccionario panhispánico de dudas. Madrid: Santillana.

REAL ACADEMIA ESPAÑOLA Y ASOCIACIÓN DE ACADEMIAS DE LA LENGUA ESPAÑOLA (2010a). Ortografía de la lengua española. Madrid: Santillana.

REAL ACADEMIA ESPAÑOLA Y ASOCIACIÓN DE ACADEMIAS DE LA LENGUA ESPAÑOLA (2010b). Nueva gramática de la lengua española. Madrid: Santillana.

REAL ACADEMIA ESPAÑOLA Y ASOCIACIÓN DE ACADEMIAS DE LA LENGUA ESPAÑOLA (2014). Diccionario de la Lengua Española. Madrid: Santillana.

TORRES TORRES, A. (2010). "El español de América en los Estados Unidos” en La lengua española en América: normas y usos actuales. (Coord. M. Aleza). Valencia: Universitat de València: 403-427.

VIGARA, A. M. (2005). Morfosintaxis del español coloquial. Madrid: Gredos. 